\title{
Hydrogen Production from a Combination of the Water-Gas Shift and Redox Cycle Process of Methane Partial Oxidation via Lattice Oxygen over $\mathrm{LaFeO}_{3}$ Perovskite Catalyst
}

\author{
Xiao Ping Dai, ${ }^{\dagger, *}$ Qiong Wu, Ran Jia Li, ${ }^{\ddagger}$ Chang Chun Yu, ${ }^{*,+}$ and Zheng Ping Hao, ${ }^{* \dagger}$ \\ Research Center for Eco-Environmental Science, Chinese Academy of Sciences, Beijing 100085, \\ P. R. China, and The Key Laboratory of Catalysis CNPC, University of Petroleum, Beijing 102249, \\ P. R. China
}

Received: August 23, 2006; In Final Form: October 12, 2006

\begin{abstract}
A redox cycle process, in which $\mathrm{CH}_{4}$ and air are periodically brought into contact with a solid oxide packed in a fixed-bed reactor, combined with the water-gas shift (WGS) reaction, is proposed for hydrogen production. The sole oxidant for partial oxidation of methane (POM) is found to be lattice oxygen instead of gaseous oxygen. A perovskite-type $\mathrm{LaFeO}_{3}$ oxide was prepared by a sol-gel method and employed as an oxygen storage material in this process. The results indicate that, under appropriate reaction conditions, methane can be oxidized to $\mathrm{CO}$ and $\mathrm{H}_{2}$ by the lattice oxygen of $\mathrm{LaFeO}_{3}$ perovskite oxide with a selectivity higher than $95 \%$ and the consumed lattice oxygen can be replenished in a reoxidation procedure by a redox operation. It is suggested that the POM to $\mathrm{H}_{2} / \mathrm{CO}$ by using the lattice oxygen of the oxygen storage materials instead of gaseous oxygen should be possibly applicable. The $\mathrm{LaFeO}_{3}$ perovskite oxide maintained relatively high catalytic activity and structural stability, while the carbonaceous deposits, which come from the dissociation of $\mathrm{CH}_{4}$ in the pulse reaction, occurred due to the low migration rate of lattice oxygen from the bulk toward the surface. A new dissociation-oxidation mechanism for this POM without gaseous oxygen is proposed based on the transient responses of the products checked at different surface states via both pulse reaction and switch reaction over the $\mathrm{LaFeO}_{3}$ catalyst. In the absence of gaseous-phase oxygen, the rate-determining step of methane conversion is the migration rate of lattice oxygen, but the process can be carried out in optimized cycles. The product distribution for POM over $\mathrm{LaFeO}_{3}$ catalyst in the absence of gaseous oxygen was determined by the concentration of surface oxygen, which is relevant with the migration rate of lattice oxygen from the bulk toward the surface. This process of hydrogen production via selective oxidation of methane by lattice oxygen is better in avoiding the deep oxidation (to $\mathrm{CO}_{2}$ ) and enhancing the selectivity. Therefore, this new route is superior to general POM in stability (resistance to carbonaceous deposition), safety (effectively avoiding accidental explosion), ease of operation and optimization, and low cost (making use of air not oxygen).
\end{abstract}

\section{Introduction}

Hydrogen is both a clean energy source and an important raw material for the chemical and refining industries. The current chemical use of hydrogen is mainly for the production of methanol, ${ }^{1,2}$ ammonia, ${ }^{3,4}$ and for hydrotreatment in refineries. ${ }^{5}$ Most hydrogen production is currently obtained from natural gas, of which the main component is methane. The most important process is the catalyzed steam reforming of methane (SMR), in combination with the water-gas shift (WGS) reaction. SMR is strongly endothermic and operated at high temperature, low pressure, and a relatively higher ratio of steam to carbon. ${ }^{6,7}$ Partial oxidation of methane (POM) to $\mathrm{H}_{2} / \mathrm{CO}$ (mildly exothermic) has recently attained more attention. In comparison with SMR, POM is more energy efficient, can be carried out at lower investment, and produces synthesis gas with a $\mathrm{H}_{2} / \mathrm{CO}$ ratio of ca. 2, which is suitable for methanol and Fischer-Tropsch synthesis. ${ }^{8} \mathrm{Ni}$ metal has been reported as the most promising catalyst system for commercialization; however, there are major drawbacks with Ni metal catalysts, such as phase

* Corresponding authors. Phone: 86-10-89707447 (C.C.Y.); 86-1062923564 (Z.P.H.). E-mail: lngcc@cup.edu.cn (C.C.Y.); zpinghao@ rcees.ac.cn (Z.P.H.)

Chinese Academy of Sciences.

$\doteqdot$ University of Petroleum. transformation, ${ }^{9}$ coke deposition, Ni sintering, ${ }^{10}$ and Ni losses. ${ }^{11}$ In addition, POM usually occurs between gas-phase oxygen and methane, which limits the selectivity of $\mathrm{CO}$ and hydrogen due to complete oxidation of methane. There are also serious safety concerns related to the direct mixing of highly explosive feed gas (methane) with oxygen at high temperature. ${ }^{12}$

Other processes in the development for hydrogen production are thermochemical cycles, ${ }^{13}$ the steam-iron process, ${ }^{14}$ twostep cyclic processes with steam, ${ }^{15}$ methane decomposition, ${ }^{16}$ catalytic coal gasification, ${ }^{17}$ and combustion reforming. ${ }^{18}$ More processes, such as photochemical, photoelectrochemical, and photobiological processes, are also being explored. ${ }^{19}$ In this paper, a new process, which combines the WGS with a redox mode using lattice oxygen as the sole oxidant instead of gaseous oxygen in a fixed-bed reactor is reported. The process will eliminate the equipment for separate air compared to the partial oxidation and, thus, reduce the investment cost. In this process the lattice oxygen $\left[\mathrm{O}_{\mathrm{L}}\right]$ selectively oxidizes methane from in situ formed $\mathrm{H}_{2} / \mathrm{CO}$. The redox process for methane conversion to $\mathrm{H}_{2} / \mathrm{CO}$ in the absence of gaseous oxygen was performed in a microreactor with a $\mathrm{LaFeO}_{3}$ perovskite catalyst, which exhibits excellent redox property, high oxygen mobility, and thermal stability. Due to their variable structure and chemical composition, $\mathrm{LaFeO}_{3}$ perovskite-type oxides have so far attracted great 


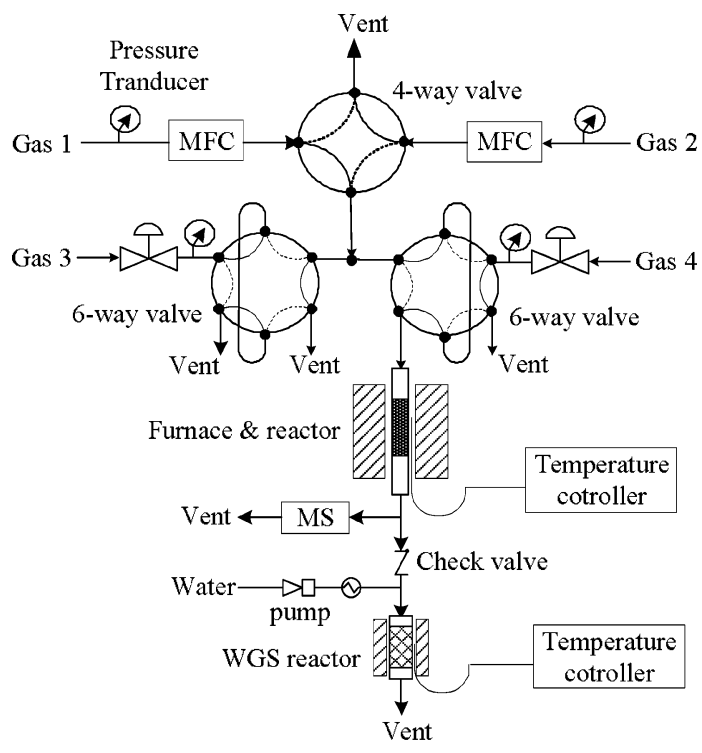

Figure 1. Schematic system of analysis for periodical operation.

interest in catalysis for hydrocarbon and $\mathrm{CO}$ deep oxidation ${ }^{20-23}$ and catalytic combustion for $\mathrm{NO}_{x}$ and soot. ${ }^{24,25}$ However, $\mathrm{LaFeO}_{3}$ perovskite-type oxides applied to the direct partial conversion of methane to synthesis gas free of gas-phase oxygen, combined with the WGS reaction for hydrogen production, have rarely been reported, and the role of lattice oxygen and the reaction mechanism for POM in the absence of gaseous oxygen over $\mathrm{LaFeO}_{3}$ catalyst were not clearly identified. In the present paper, we used pulses and the transient responses of products to investigate the POM reaction over the $\mathrm{LaFeO}_{3}$ catalysts. On the basis of the obtained results we identified and proposed the active sites and the reaction mechanism.

\section{Experimental Section}

Material Preparation. The $\mathrm{LaFeO}_{3}$ oxides were prepared by the sol-gel method. Glycine was added into an aqueous mixed solution of the metal nitrates $\left(\mathrm{La}\left(\mathrm{NO}_{3}\right)_{3} \cdot 6 \mathrm{H}_{2} \mathrm{O}, \mathrm{Fe}\left(\mathrm{NO}_{3}\right)_{3} \cdot\right.$ $9 \mathrm{H}_{2} \mathrm{O},>99 \%$, Beijing Chemical Company) and kept at a ratio of $\mathrm{NH}_{3} / \mathrm{NO}_{3}{ }^{-}=1.05$. Water was evaporated slowly from the mixed solution at $353-363 \mathrm{~K}$ until a viscous gel was obtained. The gel was then heated at $523 \mathrm{~K}$ for $30 \mathrm{~min}$ with a fast exothermic reaction, and the temperature was raised to $1173 \mathrm{~K}$ at a rate of $10 \mathrm{~K} / \mathrm{min}$ in air. The yielded brown powder precursor was calcined at $1173 \mathrm{~K}$ for $10 \mathrm{~h}$. The samples were crushed, ground, and sieved for experiment.

Material Characterizations. Phase analysis and lattice parameters were performed by X-ray powder diffraction (XRD) using a ShiDU XRD-6000 diffractometer with Ni-filtered $\mathrm{Cu}$ $\mathrm{K} \alpha$ radiation.

BET surface areas of the samples were measured by nitrogen adsorption/desorption at liquid nitrogen temperature, using a NOVA1200 gas adsorption analyzer.

Experimental Setup and Procedures. The experimental setup for a periodical operation is shown in Figure 1 and consists of three main parts: a gas flow system, two reactors with a temperature controller, and an online-detection mass spectrometer (AMETEC Quadlink 1000). The first quartz tube reactor, with an i.d. of $\Phi 6 \mathrm{~mm}$ and length of $400 \mathrm{~mm}$, is placed in an electric furnace that can be operated in pulse reaction, redox cycles. The redox cycle was operated with a four-way valve, and pulse experiments were performed using a six-way sampling valve with a $0.75 \mathrm{~mL}$ quantitative tube. A measured volume of reactant is passed through the catalyst bed in a prescribed

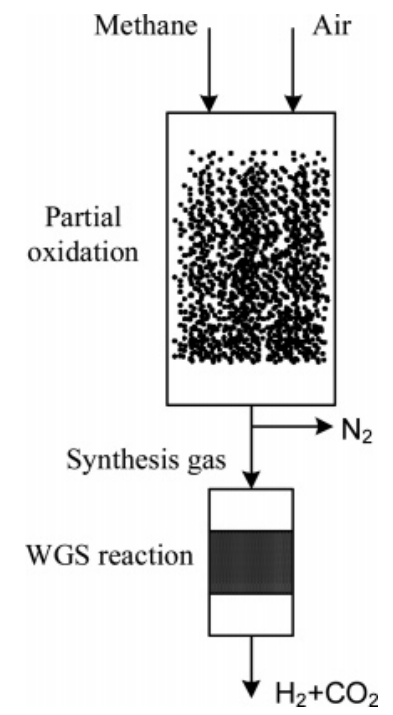

Figure 2. Schematic of periodical operation.

amount, and the reactor effluent can be analyzed online by the quadruple mass spectrometer. A redox cycle consists of a reductive atmosphere (flow of a reductive gas at a set flow rate) followed by an oxidative atmosphere (flow of oxidative gas for a measured amount). Another reactor for the WGS reaction is filled with commercial $\mathrm{Cu}-\mathrm{Zn}$ catalyst (Nanjing Chemical Industry Group).

The temperature inside the reactor bed is controlled by an AI-FUZZY temperature controller using a K-type thermal couple. The catalyst is packed in the middle of the reactor bed, and the free space of the reactor is filled with 20 to 40 mesh quartz particles. The quadruple mass spectrometer can detect eight mass channels simultaneously with the minimum dwell time of $3 \mathrm{~ms}$.

Pulse Reactions. The pulse reactions were carried out in a fixed-bed reactor; the catalyst $(0.2 \mathrm{~g})$ was primarily heated in an $\mathrm{Ar}$ stream at $1173 \mathrm{~K}$. A pulse of $\mathrm{CH}_{4}$ gas was introduced with a six-port gas sampling valve equipped with quantitative tubes $(0.75 \mathrm{~mL})$, under a stream of Ar carrier gas. The total gas flow rate was maintained at $25 \mathrm{~mL} / \mathrm{min}$.

Sequential Redox Mode. Sequential optimized redox cycles were performed over the $\mathrm{LaFeO}_{3}$ oxide for the production of $\mathrm{H}_{2} / \mathrm{CO}$ in a fixed-bed reactor at $1173 \mathrm{~K}$ between reductive $\left(\mathrm{CH}_{4} /\right.$ $\mathrm{He})$ and oxidative atmospheres $\left(\mathrm{O}_{2} / \mathrm{Ar}\right)$ (denoted as "redox"). The total gas flow rate was $25 \mathrm{~mL} / \mathrm{min}$. Ar/He was used as the dilution gas and tracer gas.

The different reaction products were detected by the mass spectrometer at $m / e=2\left(\mathrm{H}_{2}\right), m / e=15\left(\mathrm{CH}_{4}\right), m / e=18\left(\mathrm{H}_{2} \mathrm{O}\right)$, $m / e=28(\mathrm{CO}), m / e=32\left(\mathrm{O}_{2}\right)$, and $m / e=44\left(\mathrm{CO}_{2}\right)$. The $\mathrm{CH}_{4}$, $\mathrm{CO}, \mathrm{H}_{2}$, and $\mathrm{CO}_{2}$ pure pulses were injected in order to calculate the amount of $\mathrm{CH}_{4}, \mathrm{CO}$, and $\mathrm{CO}_{2}$ on the catalysts taking into account a previous calibration of the mass spectrometer. The calibration of the mass spectrometer was carried out with standard gas mixtures (known composition). The cracking coefficients of methane, $\mathrm{CO}$, and $\mathrm{CO}_{2}$ have been determined and used to calculate their concentrations. The $\mathrm{CO}$ selectivity is defined as $\mathrm{CO} /\left(\mathrm{CO}+\mathrm{CO}_{2}\right) \times 100 \%$.

\section{Results and Discussion}

Hydrogen Production by Sequential Optimized Redox Cycles. As shown in Figure 2, the catalyst is located in a single reactor and the lattice oxygen $[\mathrm{O}]_{\mathrm{L}}$ of the catalyst is the sole oxidant for the POM in situ, producing $\mathrm{H}_{2} / \mathrm{CO}$ by a redox process. Typically, the WGS reaction is an integral part for the 
hydrogen production and is used to convert $\mathrm{CO}$ in the synthesis gas to generate more $\mathrm{H}_{2}$.

The main catalytic reactions involved in this process for hydrogen production are POM with lattice oxygen, recovery of lattice oxygen with gaseous $\mathrm{O}_{2}$ or air, and WGS for $\mathrm{CO}$ removal. For the WGS reaction, related catalysts have been optimized for many years, so in this work we did not take more efforts on it.

As the lattice oxygen of the catalyst becomes depleted in the reduction reaction with methane, it should be replenished by gaseous oxygen in a subsequent reoxidation step. Thereafter, a new redox cycle could be started up again.

The reduction step:

$$
\mathrm{CH}_{4}(\mathrm{~g})+[\mathrm{O}]_{\mathrm{L}} \stackrel{\text { partial oxidation }}{\longrightarrow} \mathrm{CO}(\mathrm{g})+\mathrm{H}_{2}(\mathrm{~g})+[]_{\mathrm{L}}
$$

The reoxidation step of the reduced catalyst:

$$
[]_{\mathrm{L}}+\text { air } \rightarrow[\mathrm{O}]_{\mathrm{L}}+\mathrm{N}_{2}(\mathrm{~g})
$$

WGS reaction:

$$
\mathrm{CO}(\mathrm{g})+\mathrm{H}_{2} \mathrm{O}(\mathrm{g}) \rightarrow \mathrm{H}_{2}(\mathrm{~g})+\mathrm{CO}_{2}(\mathrm{~g})
$$

Where:

$$
\begin{array}{ll}
{[\mathrm{O}]_{\mathrm{L}}} & \text { lattice oxygen } \\
{[]_{\mathrm{L}}} & \text { oxygen vacancy }
\end{array}
$$

According to the Mars-Van Krevelen mechanism, ${ }^{26}$ two independent steps should be distinguished as the $\mathrm{CH}_{4}$ oxidation reaction and oxygen recovered by redox cycles:

$$
\begin{gathered}
\mathrm{CH}_{4}(\mathrm{~g})+\mathrm{O}_{\mathrm{L}} * \rightarrow \text { Pro }+[*] \\
2[*]+\mathrm{O}_{2}(\mathrm{~g}) \rightarrow 2\left[\mathrm{O}_{\mathrm{L}}\right]^{*}
\end{gathered}
$$

where Pro are the products, $\mathrm{O}^{*}$ are the oxidized sites, and [*] are the reduced sites. Separation of the reduction and oxidation steps is optimized for the operating conditions of each step. A sweeping step with inert gases between the reduction and oxidation steps for desorption of adsorbed oxygen on the surface is involved.

The redox experiments over $0.25 \mathrm{~g}$ of $\mathrm{LaFeO}_{3}$ catalyst were tested at $1173 \mathrm{~K}$ isothermal conditions, in atmospheric pressure between $\mathrm{O}_{2} / \mathrm{Ar}\left(11 \% \mathrm{O}_{2}\right.$ by mol, $\left.10 \mathrm{~s}\right)$ and $\mathrm{CH}_{4} / \mathrm{He}\left(11 \% \mathrm{CH}_{4}\right.$ by mol, $30 \mathrm{~s})$. The reaction temperature was determined previously to produce a level of conversion suitable for study. $\mathrm{Ar} / \mathrm{He}$ was used as the dilution gas and tracer gas, and the results are shown in Figure 3.

Figure 3 indicates the reactants and products formation responses during the cyclic reactions between $\mathrm{O}_{2} / \mathrm{Ar}$ oxidation for $10 \mathrm{~s}$ and $\mathrm{CH}_{4} / \mathrm{He}$ reduction for $30 \mathrm{~s}$ over the $\mathrm{LaFeO}_{3}$ catalyst at $1173 \mathrm{~K}$. In the first cycle, the methane was oxidized totally first by very reactive oxygen species over fresh $\mathrm{LaFeO}_{3}$ catalyst to form $\mathrm{CO}_{2}$ and $\mathrm{H}_{2} \mathrm{O}$, and then $\mathrm{CO}$ and $\mathrm{H}_{2}$ were detected when the concentration of very reactive oxygen species declined. When the lattice oxygen consumed at reductive atmospheres $\left(\mathrm{CH}_{4} / \mathrm{He}\right)$ was restored partially at oxidative atmospheres for a short time (10 s), the oxidation level of the catalyst may not reach the initial state, while most of the oxygen species, which can react with $\mathrm{CH}_{4}$ to form $\mathrm{H}_{2}+\mathrm{CO}$, can be regenerated again by gaseous oxygen during the reoxidation step. From the second redox cycle to the sixth redox cycle, the conversion enhanced slowly, and $\mathrm{CO}_{2}$ was not measured, while the selectivity to $\mathrm{CO}$

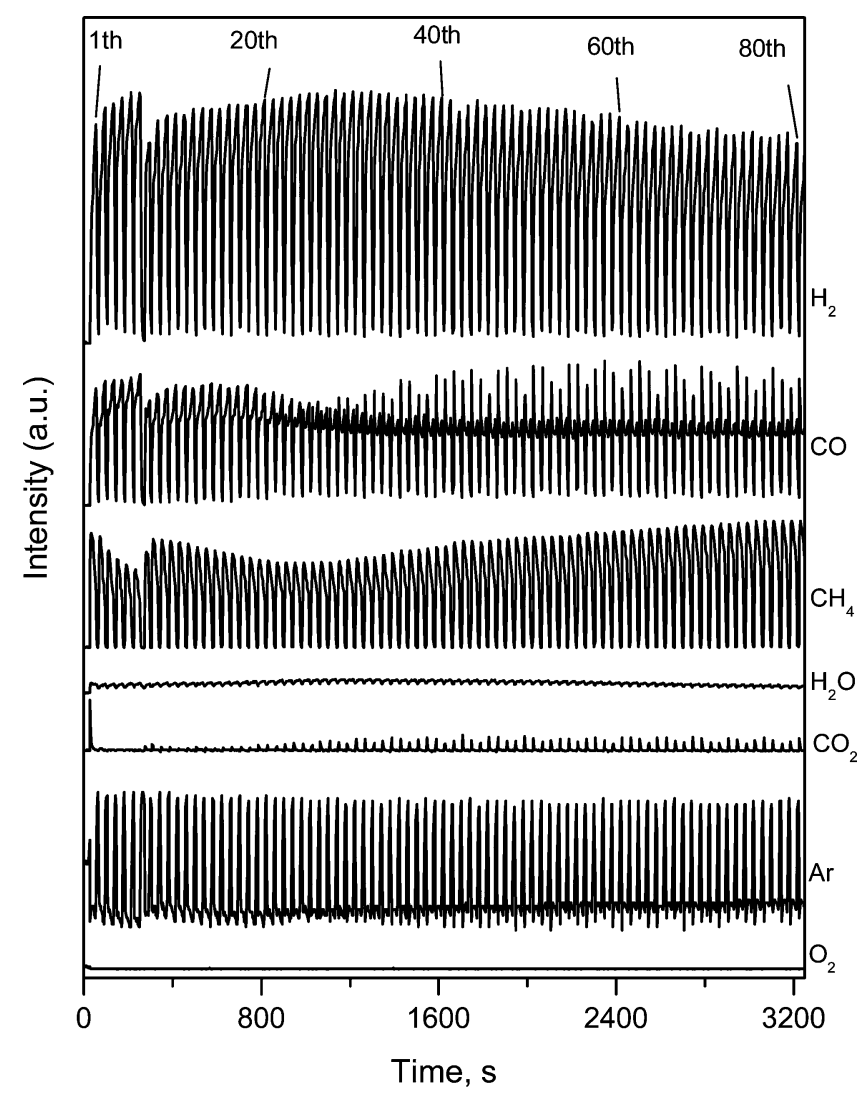

Figure 3. Reactants and products formation responses of optimized redox operation over $\mathrm{LaFeO}_{3}$ oxide at $1173 \mathrm{~K}$ isothermal conditions.

increased, and $\mathrm{H}_{2}+\mathrm{CO}$ were the dominant products. But from the seventh cycle, the amount of $\mathrm{CO}_{2}$ declined to a lower level and increased with redox number, while the selectivity to $\mathrm{CO}$ remained at a higher level $(>96 \%)$. The $\mathrm{CH}_{4}$ conversion remained at a level of $60-70 \%$ during the whole redox experiments, but it decreased slightly with the increase of cyclic number; it is observed from the change of $\mathrm{CH}_{4}$ intensity. The ratio of $\mathrm{H}_{2} / \mathrm{CO}$ is about 1.93 and close to the stoichiometric ratio of the POM. The results of reoxidation at $1173 \mathrm{~K}$ isothermal conditions on the reduced $\mathrm{LaFeO}_{3}$ catalyst show that the $\mathrm{LaFeO}_{3}$ oxide has a high reactivity toward the oxygen, which is not detected during the redox experiment. $\mathrm{CO}_{2}$ or $\mathrm{CO}$ originating from carbonaceous deposits on the catalyst surface was not observed at oxidative atmospheres of redox cycles. This indicates that the carbon species over active sites from the dissociation of methane can be consumed completely to form synthesis gas at the appropriate reaction condition.

These results indicate that the less reactive oxygen species for the $\mathrm{CO}$ formation can be regenerated, while the very reactive oxygen species for the $\mathrm{CO}_{2}$ formation is recovered hardly at appropriate condition. The $\mathrm{LaFeO}_{3}$ catalyst was exposed to extremely high temperatures exceeding $1173 \mathrm{~K}$ and experienced fluctuation between reductive and oxidative (redox) atmospheres during the 80 redox cycles, which exhibited relatively high catalytic activity and structural stability from XRD characterization (as shown in Figures 3 and 4), which was observed by Ciambelli et al.,22 but the quantity of $\mathrm{CO}_{2}$ increased with redox number, and the appearance of a deactivation phenomena may be due to the change of the redox properties of Fe. The reduction of the iron cations of perovskite to metallic iron was observed over $873 \mathrm{~K}$ by Frank et al. ${ }^{27}$ The sintering of iron oxide was found by $\mathrm{Li}$ and $\mathrm{Shen}^{28}$ and Mccart and Wise ${ }^{29}$ when the temperature exceeds $1173 \mathrm{~K}$; their experimental results are 


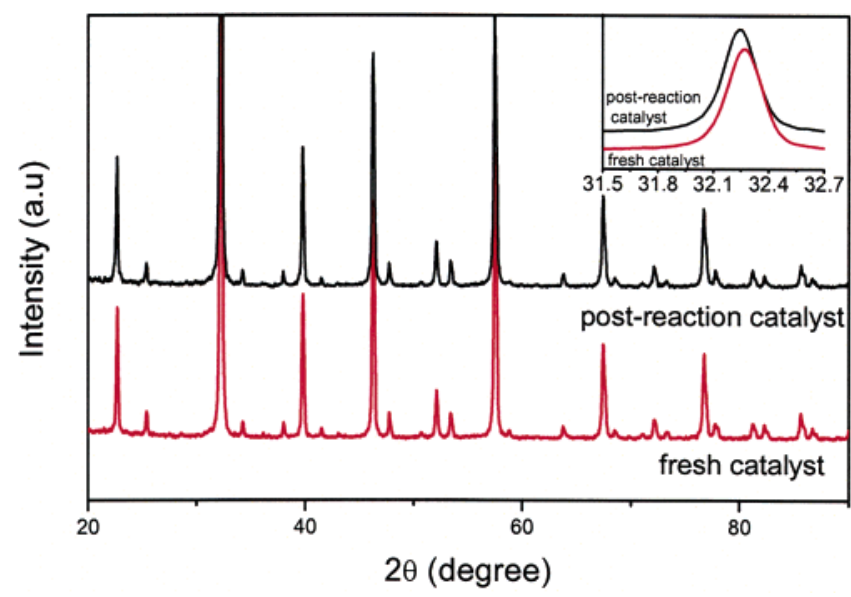

Figure 4. Comparison of XRD profiles over pre- and postreaction $\mathrm{LaFeO}_{3}$ catalyst.

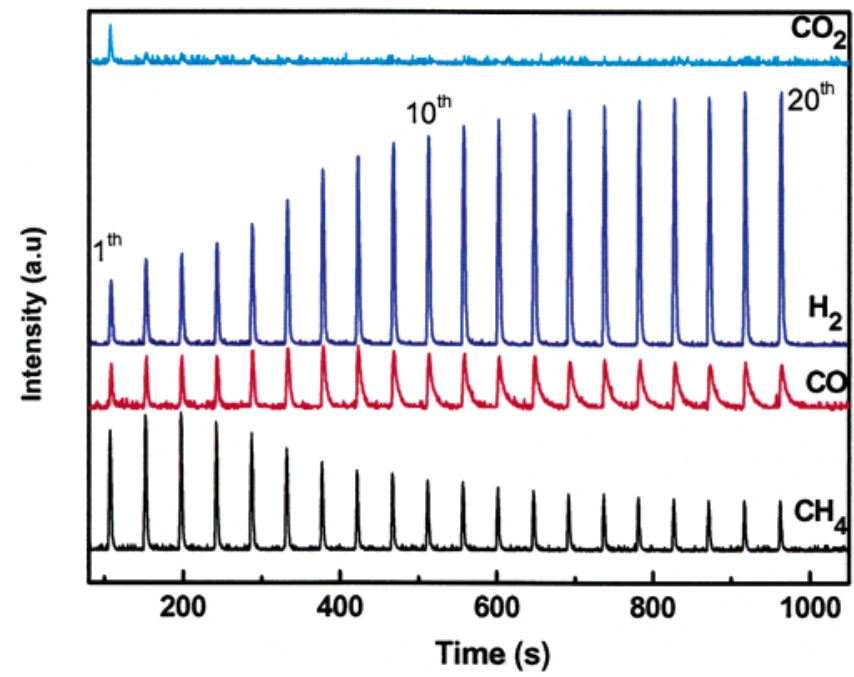

Figure 5. Methane pulse reaction over fully oxided $\mathrm{LaFeO}_{3}$ catalyst at $1173 \mathrm{~K}$.

similar to our observation, which confirms the reason of deactivation phenomena.

According to the results above, it is reasonable that methane is oxidized by the lattice oxygen species and then can be replenished by the oxygen of the atmosphere. Under steady conditions, some vacant sites could be reduced by feed gas methane, and some of the reduced $\mathrm{LaFeO}_{3}$ catalyst could be reoxidized by molecular oxygen, which is the main route for replenishing the lattice oxygen. So it is possible that POM to $\mathrm{H}_{2}+\mathrm{CO}$ by using the lattice oxygen of oxides instead of molecular oxygen over a $\mathrm{LaFeO}_{3}$ catalyst can occur by a redox mode.

Pulse Reaction. For this reaction, the 20 pulses of methane were injected continuously over $\mathrm{LaFeO}_{3}$ catalyst. The catalyst was the fresh sample after calcination and had been pretreated in situ with pulses of oxygen at $1173 \mathrm{~K}$ to ensure complete oxidation. There was no reoxidation step between the two continuous pulses of methane.

The product distributions of $\mathrm{CH}_{4}$ continuous pulses over $\mathrm{LaFeO}_{3}$ catalyst at $1173 \mathrm{~K}$ isothermal conditions are shown in Figure 5, and the $\mathrm{CH}_{4}$ conversion is illustrated in Figure 6. It is obvious that $\mathrm{CH}_{4}$ conversion for the first pulse is $\sim 50 \% ; \mathrm{H}_{2}$ and $\mathrm{CO}$ are the dominant products with a $\mathrm{CO}$ selectivity of $87 \%$ (the selectivity to $\mathrm{CO}_{2}$ was low, 13\%). After the second pulse, the selectivity of $\mathrm{CO}_{2}$ decreases to zero and $\mathrm{CO}$ selectivity increases sharply. The higher conversions of methane are

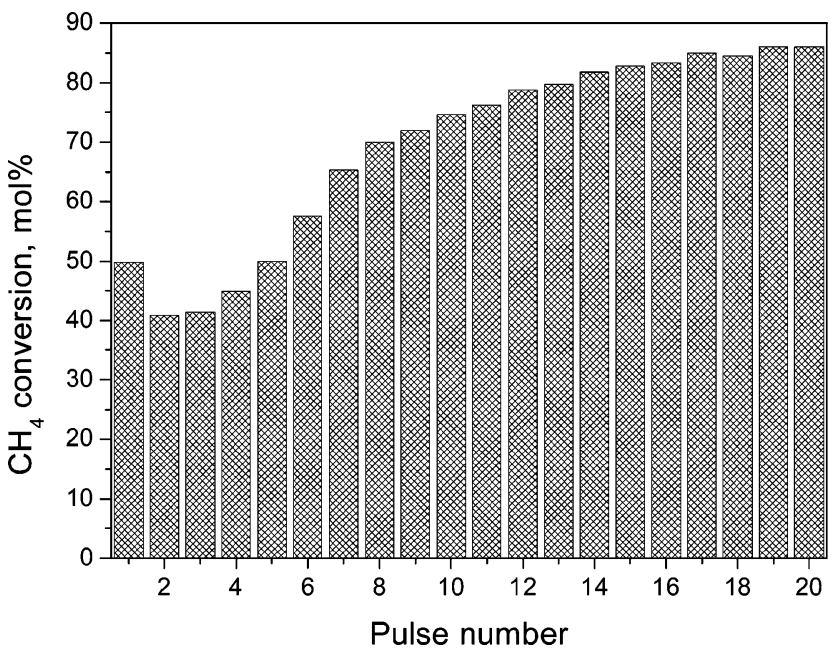

Figure 6. Methane conversion vs pulse number over fully oxided $\mathrm{LaFeO}_{3}$ catalyst at $1173 \mathrm{~K}$.

maintained at the level of $80 \%$ with the increasing pulse number (as shown in Figure 6). Obviously, the amount of oxygen can not only be ascribed to the surface oxygen, because of the amount of oxygen at the first surface layer on the basis of the low BET surface area (ca. $6 \mathrm{~m}^{2} / \mathrm{g}$ oxide calcined at $1173 \mathrm{~K}$ ). Therefore, it is clear that the bulk lattice oxygen of $\mathrm{LaFeO}_{3}$ oxide should participate in the partial oxidation of $\mathrm{CH}_{4}$ to $\mathrm{H}_{2}$ $+\mathrm{CO}$. Exposure of $\mathrm{LaFeO}_{3}$ oxides to a reduced atmosphere can generate oxygen vacancies due to the loss of lattice oxygen and reduction of the oxidative state of the Fe ion simultaneously, providing pathways of oxygen transport through the lattice, ${ }^{30}$ which decrease the resistance of oxygen migration and lead to enhancement of oxygen diffusivity. The relationship between the rate of oxygen migration and concentration of oxygen vacancies has been confirmed by Rossetti and Forni. ${ }^{31}$ It can be speculated that $\mathrm{H}_{2}+\mathrm{CO}$ is generated with a constant rate on the regular surface sites including those on the exposed surface of microdomains. Since there was no gas-phase oxygen present in the system, it implies that the surface oxygen species were from lattice oxygen, which would originate from the reduction of $\mathrm{Fe}^{3+}$ to $\mathrm{Fe}^{2+}$ and further to metallic $\mathrm{Fe}$ in $\mathrm{LaFeO}_{3}$ oxide. $^{32}$ As the number of pulses is increased, the catalyst surface becomes more and more reduced and the synthesis gas formation rises, while the $\mathrm{CO}_{2}$ formation tends toward zero. Upon further pulsing, dissociation of $\mathrm{CH}_{4}$ resulted in a higher $\mathrm{H}_{2}$ signal, and carbon deposition occurred on the $\mathrm{LaFeO}_{3}$ surface due to the lower concentration of oxygen species around the dissociative $\mathrm{C}^{*}$ on the active sites.

After 20 pulses of $\mathrm{CH}_{4}$, only $\mathrm{CO}$ was formed during pulsing with oxygen, as shown in Figure 7 . In the pulse reaction, only $\mathrm{H}_{2}$ was detected and no $\mathrm{H}_{2} \mathrm{O}$ could be found. A large amount of $\mathrm{CO}$ was produced for the three pulses of $\mathrm{O}_{2}$, while no $\mathrm{CO}_{2}$ was detected. These could be the oxidation of the carbonaceous deposits on the catalyst surface, which originated from the methane dissociation. This is similar to the observations for $\mathrm{LaFeO}_{3}$ perovskite reported by Belessi et al. ${ }^{33}$ and Liu et al. ${ }^{34}$ Moreover, in the first seven oxygen pulses, gaseous oxygen was completely consumed, which shows that $\mathrm{LaFeO}_{3}$ catalyst has a high reactivity toward with gaseous oxygen. Oxygen was not detected until the eighth pulse. Constant oxygen signals were observed after the ninth pulse, and no products were detected. Obviously, the total amount of oxygen atoms in $\mathrm{O}_{2}, \mathrm{CO}$, and $\mathrm{CO}_{2}$ detected in the effluent was less than the oxygen pulsed for the first 12 pulses. Reoxidation includes the surface adsorption of oxygen and the migration of adsorbed oxygen to 


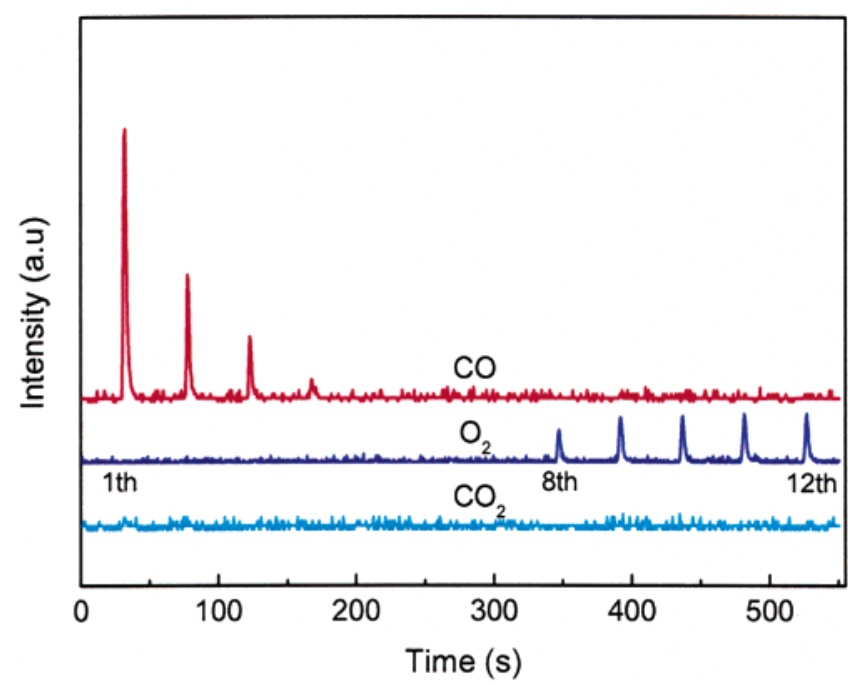

Figure 7. Oxygen pulse reaction over reacted $\mathrm{LaFeO}_{3}$ catalyst at 1173 K.

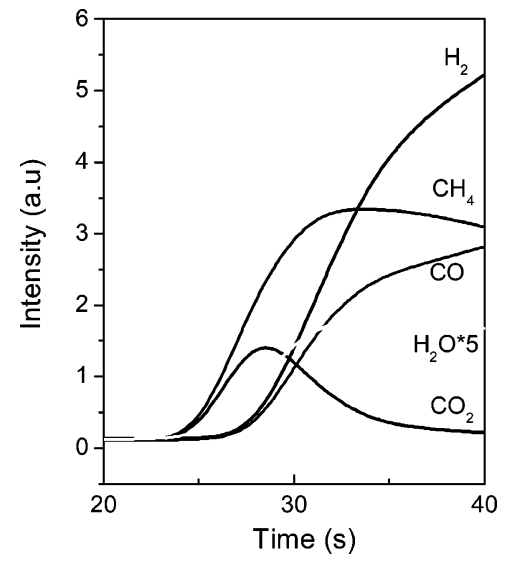

Figure 8. Transient responses of products switched from Ar to $\mathrm{CH}_{4}$ over fully oxidized $\mathrm{LaFeO}_{3}$ catalyst at $1173 \mathrm{~K}$.

oxygen vacancies in the bulk. The missing oxygen was apparently changed into the oxygen vacancy lattice position in the catalyst via reoxidation of the catalyst.

With a constant rate of the $\mathrm{CO}$ release, the rate of lattice oxygen migration is supposed to the rate-determining step, rather than the activation of methane on the surface sites for the partial oxidation reaction in the absence of gaseous oxygen. The carbonaceous deposits, coming from the dissociation of $\mathrm{CH}_{4}$, accumulated due to the low migration rate of lattice oxygen from the bulk toward the surface over the $\mathrm{LaFeO}_{3}$ catalyst.

Role of Oxygen Species and Reaction Mechanism over $\mathrm{LaFeO}_{3}$ Catalyst without Gaseous Oxygen. The reaction between the lattice oxygen of the $\mathrm{LaFeO}_{3}$ catalyst and methane without gaseous oxygen was also carried out by transient response of the products at different surface states in order to investigate the role of lattice oxygen and the reaction mechanism for methane conversion at $1173 \mathrm{~K}$ isothermal conditions. All the results are shown in Figures 8-10.

The product profiles in the switch reaction from Ar to $\mathrm{CH}_{4}$ on the fully oxidized $\mathrm{LaFeO}_{3}$ catalyst are shown in Figure 8. There is a delay between $\mathrm{H}_{2}, \mathrm{CO}$ and $\mathrm{H}_{2} \mathrm{O}, \mathrm{CO}_{2}$. With the concentration of surface oxygen declined, $\mathrm{H}_{2}$ and $\mathrm{CO}$ appear to be produced over the $\mathrm{LaFeO}_{3}$ catalyst in the absence of gaseous oxygen. We analyzed the evidence for the participation of lattice oxygen in the oxidation. The evolution of products stems from exposing the oxidized catalyst to methane. The $\mathrm{CO}_{2}$ and $\mathrm{H}_{2} \mathrm{O}$ were formed first, then $\mathrm{CO}$ and $\mathrm{H}_{2}$ were detected for

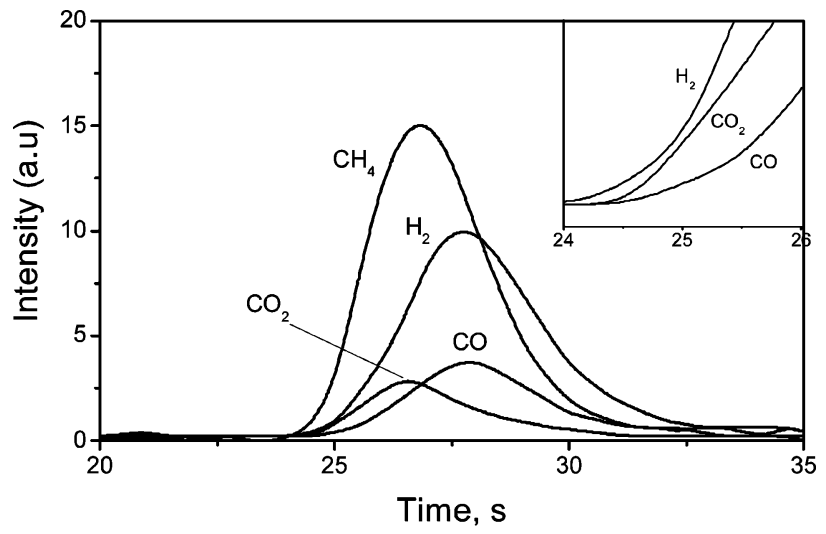

Figure 9. Response curves of products for the $\mathrm{CH}_{4}$ pulse reaction on fully oxidized $\mathrm{LaFeO}_{3}$ catalyst at $1173 \mathrm{~K}$.

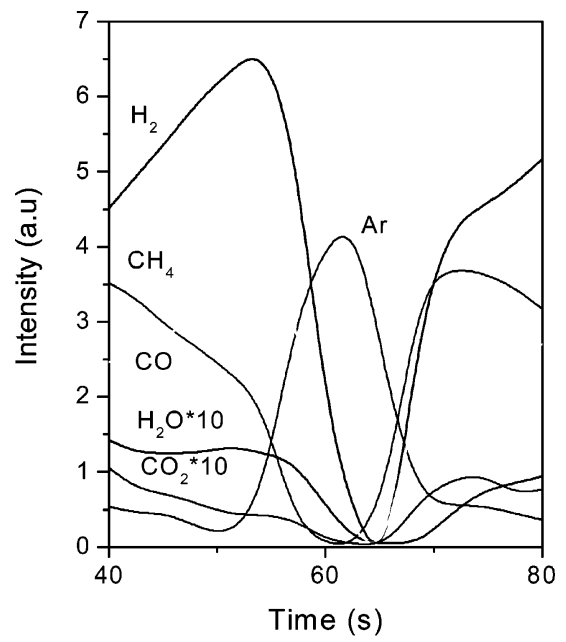

Figure 10. Product profiles obtained switch $\mathrm{CH}_{4} \rightarrow \mathrm{Ar} / \mathrm{O}_{2} \rightarrow \mathrm{CH}_{4}$ over partially oxidized $\mathrm{LaFeO}_{3}$ catalyst at $1173 \mathrm{~K}$.

the switch reaction over the fully oxidized $\mathrm{LaFeO}_{3}$ catalyst. But the intensity of $\mathrm{CO}_{2}$ did not decline immediately when the $\mathrm{CO}$ began to be detected. This indicates that the $\mathrm{CO}$ and $\mathrm{H}_{2}$ are not the products of $\mathrm{CH}_{4}$ reforming with $\mathrm{CO}_{2}$ and $\mathrm{H}_{2} \mathrm{O}$. The results in Figure 9 indicate that the products $\left(\mathrm{CO}_{2}, \mathrm{CO}\right.$, and $\left.\mathrm{H}_{2}\right)$ are detected by the mass spectrometer with a various delay compared to that of $\mathrm{CH}_{4}$. We define the time as the induction period for methane dissociation. The responses of $\mathrm{CO}$ and $\mathrm{CO}_{2}$ are detected simultaneously, but they are delayed compared to that of $\mathrm{H}_{2}$. The $\mathrm{CH}_{x}{ }^{*}$ or $\mathrm{C}^{*}$ species react further with lattice oxygen to form $\mathrm{CO}$ and $\mathrm{CO}_{2}$ through two different surface reaction routes which compete with each other, while adsorbed $\mathrm{H}$ atoms from the dissociation of methane may combine to form hydrogen and desorb easily to the gas phase from the active sites. Figure 10 shows the response profiles of products obtained during the switch $\mathrm{CH}_{4} \rightarrow \mathrm{Ar} / \mathrm{O}_{2} \rightarrow \mathrm{CH}_{4}$ over partially oxidized $\mathrm{LaFeO}_{3}$ catalyst at $1173 \mathrm{~K}$. The oxygen species of the reducedstate $\mathrm{LaFeO}_{3}$ is recovered partially by gaseous oxygen. As compared with fully oxidized $\mathrm{LaFeO}_{3}$ catalyst (Figure 8), water was shifted toward longer residence times over partially oxidized $\mathrm{LaFeO}_{3}$ catalyst. The amount of $\mathrm{CO}_{2}$ decreases obviously. These can be related to the surface state, which strengthens absorption of $\mathrm{H}_{2} \mathrm{O}$ with the active site and decreases the concentrations of surface-active oxygen species. The significant differences in the product distribution of the POM reaction over fully oxidized and partially oxidized $\mathrm{LaFeO}_{3}$ catalysts can be well related to the difference in the concentration of surface oxygen species over the $\mathrm{LaFeO}_{3}$ catalysts. The pulse responses of pure $\mathrm{H}_{2}$ and pure $\mathrm{CO}$ indicated that the reaction between $\mathrm{H}_{2}$ and lattice 
oxygen over partially oxidized surface of $\mathrm{LaFeO}_{3}$ catalyst hardly occurred, while $\mathrm{CO}$ can be oxidized totally to $\mathrm{CO}_{2}$ with lattice oxygen at $1173 \mathrm{~K}$. The experimental results with methane pulses (as shown in Figures 5 and 7) also provide some insight into the mechanism of POM. Indeed, in the reaction of pure methane and lattice oxygen, a noticeable amount of carbon was deposited over the $\mathrm{LaFeO}_{3}$ catalyst (as shown in Figure 7). Of course, the generation of the surface carbon originates from methane and follows the dissociation $\mathrm{CH}_{4, \mathrm{~s}} \rightarrow \mathrm{CH}_{x, \mathrm{~s}} \rightarrow \mathrm{C}_{\mathrm{s}}$. When the concentration of surface oxygen species is high (as shown in Figure 8), the main products are $\mathrm{CO}_{2}$ and $\mathrm{H}_{2} \mathrm{O}$, while for low concentrations of surface oxygen species (as shown in Figure 10), the main products are $\mathrm{CO}$ and $\mathrm{H}_{2}$. These are relevant with the concentration of surface oxygen species around the dissociative $\mathrm{C}^{*}$ on active sites. For the $\mathrm{LaFeO}_{3}$ catalyst, a strong increase in the reduction rate with time indicates that this process proceeds through a growth of nuclei of a new reduced phase (probably metallic iron and/or its carbide). Sadykov et al. ${ }^{35}$ reported that a new reduced phase was caused by a low rate of the oxygen migration by bulk mobility of oxygen in the lanthanum ferrite lattice, which favors a rapid formation of the reduced nuclei at the surface. From the experimental results, the $\mathrm{H}_{2}+\mathrm{CO}$ formation was favored by the rapid dissociation of methane, which apparently proceeds easier on the reduced surface containing the metal/carbide clusters or nuclei.

Integrated with the results of the pulse reaction, transient responses, and redox cycle, combined with the above literature, ${ }^{27,32,35}$ the reaction mechanism can be expressed as follows:

Reduction step:

$$
\begin{gathered}
\mathrm{CH}_{4} \rightarrow \mathrm{CH}_{3}^{*}+\mathrm{H}^{*} \rightarrow \mathrm{C}^{*}+4 \mathrm{H}^{*} \\
2 \mathrm{H}^{*} \rightarrow \mathrm{H}_{2}(\mathrm{~g})+2\left[^{*}\right] \\
\mathrm{C}^{*}+\mathrm{O}^{*}(\text { surface }) \rightarrow \mathrm{CO}^{*}+[*] \rightarrow \mathrm{CO}(\mathrm{g})+2\left[^{*}\right] \\
\mathrm{CH}_{x}^{*} \text { or } \mathrm{C}^{*}+\mathrm{O}^{*}(\text { surface }) \rightarrow \mathrm{CO}_{2}+\mathrm{H}_{2} \mathrm{O} \\
\mathrm{O}(\text { bulk }) \rightarrow \mathrm{O}^{*}(\text { surface })
\end{gathered}
$$

Oxidation step:

$$
2[*]+\mathrm{O}_{2}(\mathrm{~g}) \rightarrow 2 \mathrm{O} *(\text { surface }) \rightarrow 2 \mathrm{O}(\text { bulk })
$$

Methane is dissociatively chemisorbed in step 1 . Dissociation is depicted as two steps although it probably takes place stepwise. As mentioned in the Finocchio et al.'s work, ${ }^{36}$ in the case of a more stable molecule like methane, the dissociation of the first $\mathrm{C}-\mathrm{H}$ bond requires considerably higher energy than the dissociation of a $\mathrm{C}-\mathrm{H}$ bond in the formed surface species. Adsorbed $\mathrm{H}$ atom may combine to form hydrogen and easily desorb (step 2). The chemisorbed carbon species is either oxidized to $\mathrm{CO}$ by lattice oxygen (step 3), or oxidized totally to $\mathrm{CO}_{2}$ (step 4), or forms an inactive carbon (step 1). The $\mathrm{CO}$ and $\mathrm{CO}_{2}$ originate from similar carbon-containing species, but the reactions compete with each other. The above scheme, the so-called dissociation-oxidation mechanism, is plausible, and more work is still needed to further confirm the individual steps and the intermediate species.

According to the above scheme, the product distribution for the POM reaction over $\mathrm{LaFeO}_{3}$ catalyst was determined by the concentration of surface oxygen species, which is affected by the migration rate of oxygen from the bulk toward the surface. The catalyst development for methane partial oxidation using lattice oxygen instead of gaseous oxygen must dedicate to improve the migration rate of oxygen, enhance oxygen exchange capability, increase the active sites for methane dissociation and optimize the redox cycle for hydrogen production.

\section{Conclusions}

Combined with WGS, a redox cycle process for hydrogen production in a fixed-bed reactor via a switch reaction is presented in this paper. In the redox cycle process, $\mathrm{CH}_{4}$ and $\mathrm{O}_{2}$ are periodically brought into contact with the catalyst by making use of lattice oxygen existing in the solid oxide materials instead of gaseous oxygen as the sole oxidant for POM. It was found that under an appropriate reaction conditions, methane can be oxidized to $\mathrm{CO}$ and $\mathrm{H}_{2}$ with a selectivity higher than $95 \%$ by the lattice oxygen of $\mathrm{LaFeO}_{3}$ perovskite oxide (as an oxygen donor material), and the consumed lattice oxygen can be recovered in a reoxidation procedure by a redox operation. It was proved that POM to $\mathrm{H}_{2}+\mathrm{CO}$ by using the lattice oxygen of the catalyst is possibly applicable. The carbonaceous deposits coming from the dissociation of $\mathrm{CH}_{4}$ in the pulse reaction were formed due to the low migration rate of lattice oxygen from the bulk toward the surface, which is supposed to be the ratedetermining step, rather than the activation of methane on the surface-active sites. The transient responses of products at different surface states in the pulse and switch reaction over the $\mathrm{LaFeO}_{3}$ catalyst clearly demonstrate that $\mathrm{POM}$ over $\mathrm{LaFeO}_{3}$ proceeds as a dissociation-oxidation mechanism. The product distribution for POM over $\mathrm{LaFeO}_{3}$ catalyst in the absence of gaseous oxygen was determined by the concentration of surface oxygen, which is relevant with the migration rate of lattice oxygen from the bulk toward the surface. For hydrogen production, this new route is superior to POM in terms of stability, safety, ease of operation, optimization, and cost efficiency.

Acknowledgment. Financial funds from the Chinese Natural Science Foundation (Project Nos. 20306016, 20322201) and the National Basic Research Program of China (2004CB217808, 2004CB719500) are gratefully acknowledged.

\section{References and Notes}

(1) Hindermann, J. P.; Hutching, G. J.; Kieennemann, A. Catal. Rev.Sci. Eng. 1993, 35, 1.

(2) Agrell, J.; Birgersson, H.; Boutonnet, M.; Melián-Cabrera, I.; Navarro, R. M.; Fierro, J. L. G. J. Catal. 2003, 219, 389.

(3) Nielsen, A. Catal. Rev.-Sci. Eng. 1981, 23, 17.

(4) Ozaki, A.; Aika, K. Catalysis: Science and Technology; SpringerVerlag: New York, 1981; p 106.

(5) Prins, R.; de Beer, V. H. J.; Somorjai, G. A. Catal. Rev.-Sci. Eng. 1989, 31,1 .

(6) Courty, P.; Chauvel, A. Catal. Today 1996, 29, 3.

(7) Joensen, F.; Rostrup-Nielsen, J. J. Power Sources 2002, 105, 195.

(8) Hu, Y. H.; Ruckenstein, E. J. Catal. 1996, 158, 260.

(9) Bharadwaj, S. S.; Schmidt, L. D. J. Catal. 1994, 146, 11

(10) Natesakhawat, S.; Watson, R. B.; Wang, X. Q.; Ozkan, U. S. J. Catal. 2005, 234, 496.

(11) Ji, Y. Y.; Li, W. Z.; Xu, H. Y.; Chen, Y. X. Appl. Catal., A 2001, 213,25 .

(12) Vanderstraeten, B.; Tuerlinckx, D.; Berghmans, J.; Vliegen, S.; Van't Oost, E.; Smit, B. J. Hazard. Mater. 1997, 56, 237.

(13) Steinfeld, A. Int. J. Hydrogen Energy 2002, 27, 611.

(14) Hacker, V.; Robert F., Faleschini, G.; Fuchs, H.; Friedrich, K.; Muhr, M.; Kordesch, K. J. Power Sources 2000, 86, 531.

(15) Kodama, T.; Shimizu, T.; Satoh, T.; Shimizu, K. I. Energy 2003, 28,1055 .

(16) Otsuka, K.; Mito, A.; Takenaka, S.; Yamanaka, I. Int. J. Hydrogen Energy 2001, 26, 191.

(17) Timpe, R. C.; Kulas, R. W.; Hauserman, W. B.; Sharma, R. K.; Olson, E. S.; Willson, W. G. Int. J. Hydrogen Energy 1997, 22, 487.

(18) Li, R. J.; Yu, C. C.; Dai, X. P.; Shen, S. K. Chin. J. Catal. 2002, 23,381 .

(19) Momirlan, M.; Veziroglu, T. N. Renewable Sustainable Energy Rev. 2002, 6, 141. 
(20) Spinicci, R.; Tofanari, A.; Faticanti, M.; Pettiti, I.; Porta, P. J. Mol. Catal. A: Chem. 2001, 176, 247.

(21) Choudhary, V. R.; Uphade, B. S.; Pataskar, S. G. Fuel 1999, 78, 919.

(22) Ciambelli, P.; Cimino, S.; De Rossi, S.; Lisi, L.; Minelli, G.; Porta, P.; Russo, G. Appl. Catal., B 2001, 29, 239.

(23) Ortega, F. M.; Dupeyrat, C. B.; Valderrama, G.; Tatibouët, J. M. Surf. Chem. Catal. 2001, 4, 49.

(24) Cimino, S.; Lisi, L.; Rossi, S. D.; Faticanti, M.; Porta, P. Appl. Catal., B 2003, 43, 397.

(25) Fino, D.; Russo, N.; Saracco, G.; Specchia, V. J. Catal. 2003, 217, 367

(26) Mars, P.; van Krevelen, D. W. Chem. Eng. Sci. 1954, 3 (Special Suppl.), 41.

(27) Frank, J. B.; Gancedo, J. R.; Marco, J. F.; Ren, X. L. J. Solid State Chem. 2004, 177, 2101.
(28) Li, R. J.; Shen, S. K. J. Mol. Catal. (China) 2001, 15, 181

(29) Mccart, J. G.; Wise, H. Catal. Today 1990, 8, 231.

(30) Ramos, T.; Atkinson, A. Solid State Ionics 2004, 170, 275.

(31) Rossetti, I.; Forni, L. Appl. Catal., B 2001, 33, 345.

(32) Tejuca, L. G.; Fierro, J. L. G.; Tasćon, J. M. D. Adv. Catal. 1989 $36,237$.

(33) Belessi, V. C.; Trikalitis, P. N.; Ladavos, A. K.; Bakas, T. V.; Pomonis, P. J. Appl. Catal., A 1999, 177, 53.

(34) Liu, B. C.; Tang, S. H.; Yu, Z. L.; Zhang, B. L.; Chen, T.; Zhang, S. Y. Chem. Phys. Lett. 2002, 357, 297.

(35) Sadykov, V. A.; Isupova, L. A.; Yakovleva, I. S.; Alikina, G. M.; Lukashevich, A. I.; Neophytides, S. React. Kinet. Catal. Lett. 2004, 81, 393.

(36) Finocchio, E.; Busca, G.; Lorenzelli, V.; Willey, R. J. J. Catal. $1995,151,204$ 